\title{
Fogwater Chemistry in an Urban Atmosphere
}

\author{
J. William Munger, Daniel J. Jacob, Jed M. Waldman, and Michael R. Hoffmann
}

\author{
W. M. Keck Laboratories, California Institute of Technology, Pasadena, California 91125
}

\begin{abstract}
Analyses of fogwater collected by inertial impaction in the Los Angeles basin and the San Joaquin Valley indicated unusually high concentrations of major and minor ions. The dominant ions measured were $\mathrm{NO}_{3}{ }^{-}, \mathrm{SO}_{4}{ }^{2-}, \mathrm{NH}_{4}{ }^{+}$, and $\mathrm{H}^{+}$. Nitrate exceeded sulfate on an equivalent basis by a factor of 2.5 in the central and coastal regions of the Los Angeles basin but was approximately equal in the eastern Los Angeles basin and the San Joaquin Valley. Maximum observed values for $\mathrm{NH}_{4}{ }^{+}, \mathrm{NO}_{3}{ }^{-}$, and $\mathrm{SO}_{4}{ }^{2-}$ were $10.0,12.0$, and 5.0 , meq $1^{-1}$, while the lowest $p \mathrm{H}$ observed was 2.2. Iron and lead concentrations of over 0.1 $\mathrm{m} M$ and $0.01 \mathrm{mM}$, respectively, were observed. High concentrations of chemical components in fog appeared to correlate well with the occurrence of smog events. Concentrations in fogwater were also affected by the physical processes of condensation and evaporation. Light, dissipating fogs routinely showed the highest concentrations.
\end{abstract}

\section{INTRODUCTION}

Laboratory [Schwartz, 1983; Martin, 1983; Hoffmann and $J a c o b, 1983$ ] and field [Cass and Shair, 1980; Cox, 1974; McMurry et al., 1981; Smith and Jeffery, 1975; Wilson and McMurry, 1981] studies have indicated that droplet-phase chemistry is important in $\mathrm{SO}_{2}$ oxidation. Droplet-phase oxidation of $\mathrm{SO}_{2}$ occurs, in part, via the following reactions

$$
\begin{gathered}
\mathrm{SO}_{2}(\mathrm{~g}) \stackrel{\mathrm{K}_{\mathrm{H}}}{\rightleftharpoons} \mathrm{SO}_{2}(\mathrm{aq}) \\
\mathrm{SO}_{2}(\mathrm{aq}) \stackrel{\mathrm{K}_{\mathrm{a} 1}}{\rightleftharpoons} \mathrm{H}^{+}+\mathrm{HSO}_{3}{ }^{-} \\
2 \mathrm{HSO}_{3}{ }^{-}+\mathrm{O}_{2} \stackrel{\mathrm{Fe}(\mathrm{III})}{\mathrm{Mn}(\mathrm{II})} 2 \mathrm{HSO}_{4}{ }^{-} \\
\mathrm{HSO}_{4} \stackrel{\stackrel{\mathrm{K}_{\mathrm{a} 2}}{\rightleftharpoons}}{\rightleftharpoons} \mathrm{H}^{+}+\mathrm{SO}_{4}{ }^{2-}
\end{gathered}
$$

In Los Angeles, Cass [1975] observed a correlation between the occurrence of high sulfate aerosol levels during the afternoon and the presence of coastal fog and low clouds in the morning. The mean $\mathrm{SO}_{2}$ to $\mathrm{SO}_{4}{ }^{2-}$ conversion rate during July in Los Angeles is $6 \% \mathrm{hr}^{-1}$ [Cass, 1981], whereas gas-phase reactions can account for, at most, conversion rates of $4.5 \%$ $\mathrm{hr}^{-1}$ [Sander and Seinfeld, 1976]. Morgan and Liljestrand [1980] reported that light misting rainfalls emanating from low stratus clouds in Los Angeles resulted in $\mathrm{pH}$ values as low as 2.9 with correspondingly high $\mathrm{SO}_{4}{ }^{2-}$ and $\mathrm{NO}_{3}{ }^{-}$concentrations. Waldman et al. [1982] have previously reported $p \mathrm{H}$ values near 2.2 in urban fog. Furthermore, Hegg and Hobbs [1981] have reported S(IV) to S(VI) conversion rates of 4.0 to $300 \% \mathrm{hr}^{-1}$ in wave clouds over western Washington.

In addition to its importance as a chemical reaction site, fog may exert a significant influence on scavenging and deposition, on human health, and on vegetation. Fog forms in the ground layer where gases and aerosols are most concentrated. Because fog droplets are approximately 100 times smaller than rain drops, they should be more concentrated than rain, and mass transfer should not limit the kinetics of fog droplet reactions [Schwartz, 1983; Baboolal et al., 1981].

In light of these results and the expectation that fog droplets (or the fine aerosol remaining after fog has evaporated) are sites

\section{Copyright 1983 by the American Geophysical Union.}

Paper number $3 \mathrm{C} 0293$.

0148-0227/83/003C-0293\$05.00 for rapid conversion of $\mathrm{SO}_{2}$ to $\mathrm{SO}_{4}{ }^{2-}$ we began a study to characterize the chemical composition of fogwater. Because of the physical similarity to clouds, fog is expected to exhibit the same chemical processes occurring in clouds and, to some degree, aquated submicron aerosols. Information about the chemistry of fogwater may be applicable to the broader questions about ambient acid formation and acidic precipitation. The role of fog in the nocturnal chemistry of $\mathrm{SO}_{2}$ has been examined by Jacob and Hoffmann [1983].

\section{Methods}

Fogwater was collected with a rotating arm collector (RAC), which was modified from an original design reported by Mack and Pilie [1975]. A 67.5-cm-long, Teflon-coated steel tube with $10 \times 0.95 \mathrm{~cm}$ slots milled into opposite sides at each end of the tube is rotated at $1700 \mathrm{rpm}$ with a $1.5-\mathrm{HP}$ induction motor. This rotation imparts a relative velocity of $\sim 50 \mathrm{~m} / \mathrm{s}$ to the slots. Droplets impact in the slots and are driven by centrifugal force into $30-\mathrm{ml}$ polyethylene bottles attached at the ends of the arms. During operation, the pivot of the arm is $1.4 \mathrm{~m}$ above ground level. Based upon changes in particle-size distributions measured with a laser optical particle counter during operation in a cloud chamber, the RAC was determined to have a lowersize cut of $\sim 8 \mu \mathrm{m}$ [Jacob et al., 1982]. The bulk of liquid water in fogs is contributed by droplets larger than $8 \mu \mathrm{m}$, but droplets smaller than $8 \mu \mathrm{m}$ may be more concentrated than those that are actually collected. Consequently, the concentration of species in fogwater may be slightly underestimated. With this design, up to $2 \mathrm{ml} \mathrm{min}^{-1}$ of fogwater has been collected during dense fog and 0.1 to $1.0 \mathrm{ml} \mathrm{min}{ }^{-1}$ during lighter fog. Collection efficiency under these conditions is estimated to be greater than $80 \%$, based on laboratory calibration. We are currently working on a fog sampler with a lower-size cut in order to characterize the chemistry of the smaller fog droplets.

\section{Site Descriptions}

Figure 1 indicates the sites at which fogwater was collected. The Pasadena site, which is located on the roof of a four-story building on the Caltech campus, is in a predominantly residential neighborhood $25 \mathrm{~km}$ north of downtown Los Angeles. There are no major pollutant sources in the immediate vicinity. The Lennox site was selected because of its close proximity to both industrial and mobile pollutant sources and its high frequency of marine fog in late autumn: it is situated on the roof of a one-story building at a busy intersection within $100 \mathrm{~m}$ of a 


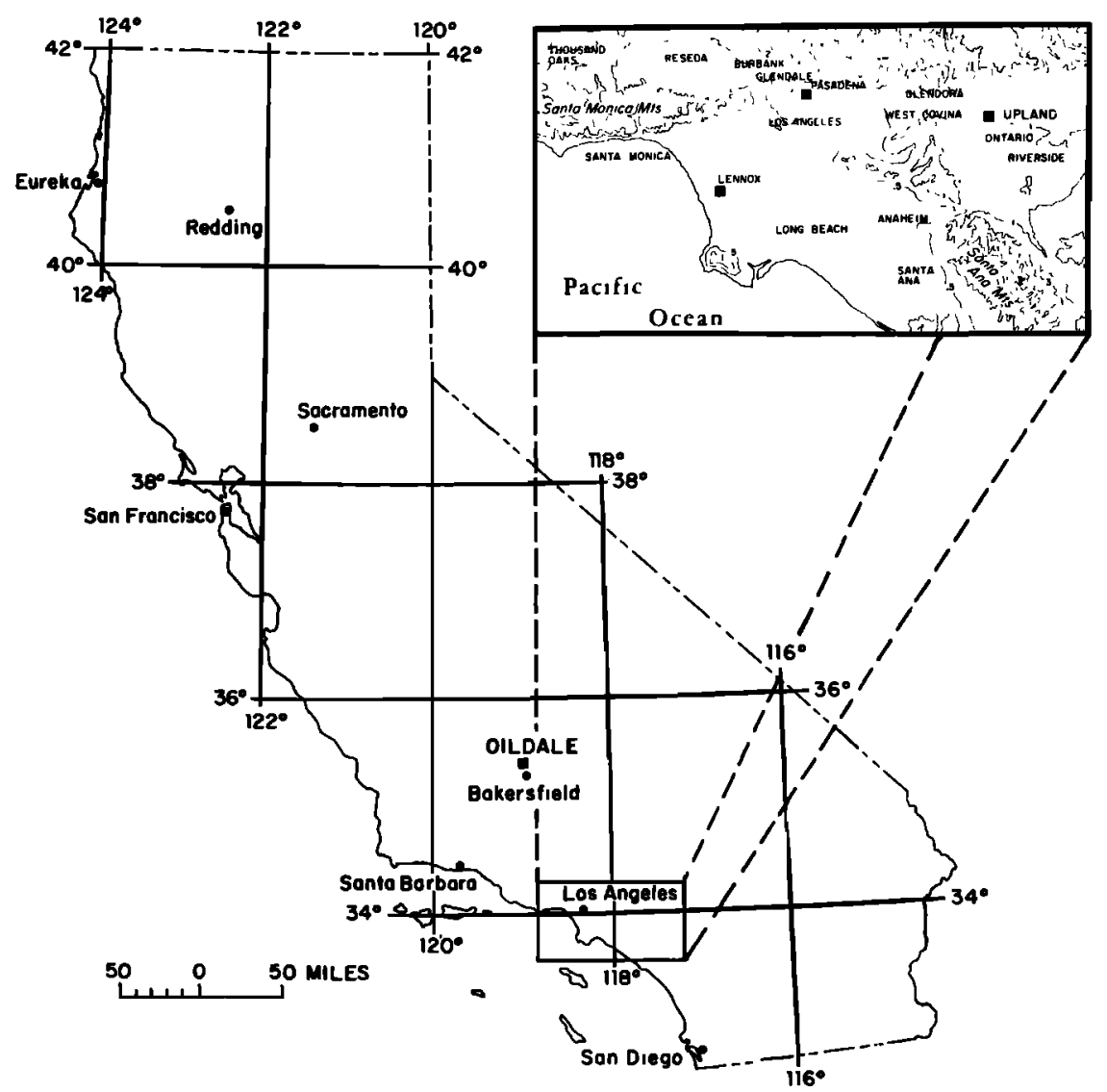

Fig. 1. Map of fog sampling sites in Southern California. Los Angeles area sites are indicated on the inset.

major freeway and $6 \mathrm{~km}$ from the ocean. Major point sources near the Lennox site include an oil refinery, power plant, Los Angeles International Airport, and several other industrial facilities.

The Oildale site, near Bakersfield, is in an area with higher sulfur emissions from secondary oil recovery operations and is subject to extensive fog ('Tule fog'), which persists throughout the San Joaquin Valley during the early winter. The sampler was placed on the roof of an air-quality monitoring station (about $4 \mathrm{~m}$ aboveground). Upland is $60 \mathrm{~km} \mathrm{NE}$ of downtown Los Angeles. A steel plant and several other heavy industries are located within $30 \mathrm{~km}$ of this site, which is also on the roof of an air-quality monitoring station in a residential area.

\section{Fog Patterns}

In Los Angeles, fog generally occurs during two distinct periods: November through January and April through June. At the two inland sites, Pasadena and Upland, fog occurs sporadically in the night and early morning throughout the fog seasons. Fogs along the coast tend to form repeatedly for several nights, lifting for only part of the day. In the San Joaquin Valley, fog forms for extended periods during the early winter months and often persists throughout the day.

\section{Analytical Methods}

The sample-handling and analytical protocol is illustrated in Figure 2. Analysis of the sample began as soon as collection ended; measurement of $p \mathrm{H}$ and separation of preserved aliquots was completed within $30 \mathrm{~min}$. In the field, samples were stored over ice, then refrigerated when brought back to the laboratory; $p H$ was determined in the field with a Radiometer PHM 80 meter. Sulfite was preserved by addition of $\mathrm{CH}_{2} \mathrm{O}$ at $p \mathrm{H} 4$ to form hydroxymethanesulfonic acid (HMSA) [Dasgupta et al., 1980; Fortune and Dellinger, 1982]; 3,5-diacetyl-1,4dihydrolutidine (DDL) formed by reaction of formaldehyde and acetyl acetone in the presence of $\mathrm{NH}_{4}{ }^{+}[\mathrm{Nash}, 1953]$ is stable for at least 7 days [Rietz, 1980]. Sulfite is known to interfere with this reaction [Nash, 1953], but no correction was made. Addition of $\mathrm{HNO}_{3}$ to achieve a concentration of $0.16 \mathrm{M}$ was used to stabilize an aliquot for trace-metal analyses. Beginning with the Oildale samples, aliquots were filtered through $0.4-\mu \mathrm{m}$ Nuclepore membranes in the field. Because of extremely high cation and anion concentrations in fogwater, samples usually had to be diluted before analysis. With sample dilution, complete analyses of volumes as small as $5 \mathrm{ml}$ was practicable.

Major cations were determined on a Varian AA5 atomic absorption spectrophotometer by using an air-acetylene flame. Lanthanum was added to the entire aliquot used for AAS in order to release calcium and magnesium. Ammonium was determined by the phenol-hypochlorite method [Solórzano, 1967]. Anions were determined by ion chromatography (IC), using a 3-m $\mathrm{M} \mathrm{NaHCO}$ /2.4-m $M \mathrm{Na}_{2} \mathrm{CO}_{3}$ eluent. Aliquots of sample were spiked to give the same $\mathrm{HCO}_{3}-/ \mathrm{CO}_{3}{ }^{2-}$ concentration as the eluent in order to eliminate the water dip that interferes with $\mathrm{F}^{-}$and $\mathrm{Cl}^{-}$peaks. Galloway et al. [1982] suggest that low molecular weight carboxylic acids are present in rainwater. Considering the high aldehyde concentrations observed in fogwater, it is likely that the corresponding acids are present as well. If present, these acids would be a positive interference with fluoride. The absorbance of DDL formed 
FOG SAMPLE-HANDLING PROTOCOL

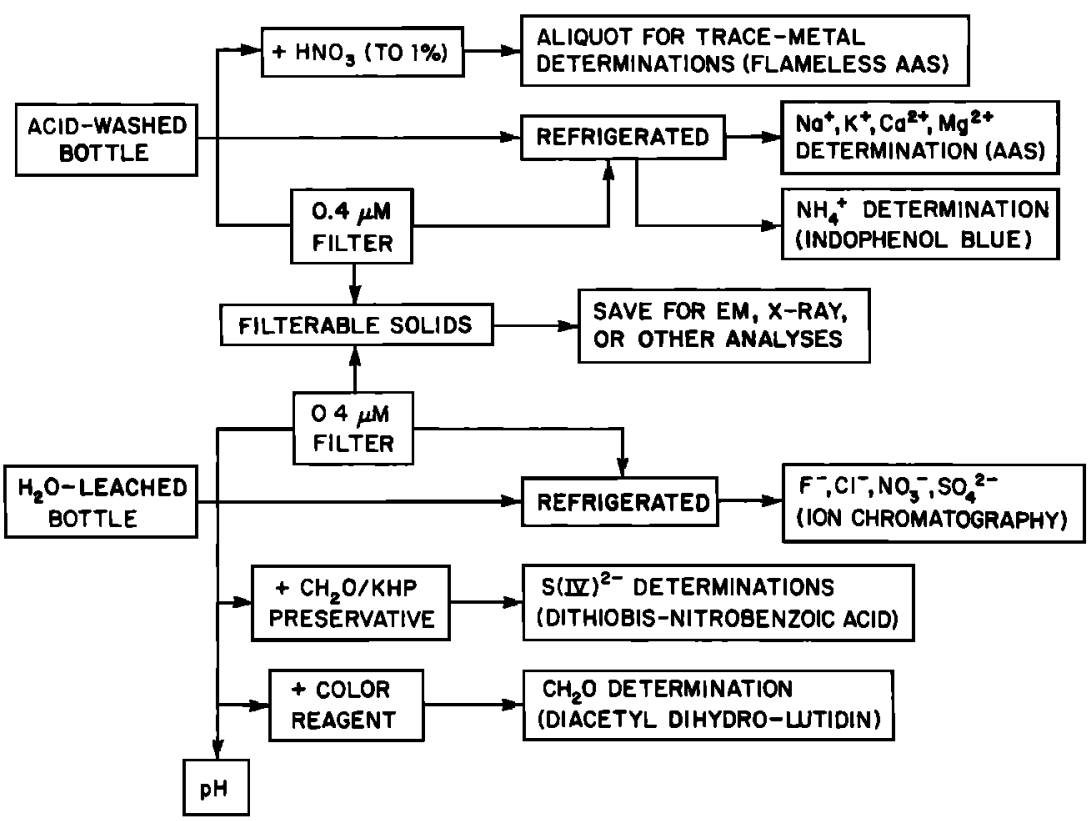

Fig. 2. A schematic flow diagram indicating fog sample-handling protocol and analytical procedures.

from $\mathrm{CH}_{2} \mathrm{O}$ was measured at $412 \mathrm{~nm}$ on a Beckman Acta III spectrophotometer.

The preserved solution for S(IV) was injected into the IC and eluted with $1 \mathrm{mM}$ KHP [Dasgupta et al., 1980]. Because the $\mathrm{F}^{-}$ and $\mathrm{Cl}^{-}$peaks coeluted with the hydroxymethanesulfonate (HMSA) using this eluent, the S(IV) in the samples could not be directly quantified. Instead, S(IV) was taken as the difference between the $\mathrm{SO}_{4}{ }^{2-}$ concentration in the preserved aliquot and the $\mathrm{SO}_{4}{ }^{2-}$ concentration in the unpreserved aliquot, measured by the usual IC methods. The first value would be $\mathrm{SO}_{4}{ }^{2-}$ only, the second would be the sum of $\mathrm{SO}_{4}{ }^{2-}$ and $\mathrm{SO}_{3}{ }^{2-}$. After
December 7, S(IV) was measured by a colorimetric method, using 5,5', Dithiobis-(2-nitrobenzoic acid) DTNB [Humphrey et al., 1970]. Trace metals were determined by flameless atomic absorption (Varian AA6 equipped with a CRA 90 or PerkinElmer 360 with a HGA 2100). Gas-phase concentrations of $\mathrm{SO}_{2}, \mathrm{NO}_{x}, \mathrm{O}_{3}$ were made continuously at the Lennox, Upland, and Oildale sites by conventional instrumental methods.

\section{RESULTS}

Table 1 describes the conditions before and during the fog sampling. Samples from Pasadena were collected both after

TABLE 1. Description of Conditions During and Before Fog Sample Collection

\begin{tabular}{|c|c|c|c|c|}
\hline Site & Date & $\begin{array}{l}\text { Sampled } \\
\text { Interval, hr }\end{array}$ & Conditions During Fog & Prior Conditions \\
\hline Pasadena & November 15,1981 & $2040-0115$ & $\begin{array}{l}\text { Light wind SSW-N; sampled } \\
\text { beginning to end of fog. }\end{array}$ & Fair, good air quality. \\
\hline Pasadena & November 23, 1981 & $2320-0130$ & $\begin{array}{l}\text { Light S-SE wind; } 14^{\circ}-12^{\circ} \mathrm{C} \\
\text { fog thickened to near } \\
\text { drizzle; sampled beginning } \\
\text { to end of fog. }\end{array}$ & Hazy and smoggy. \\
\hline Lennox & December 7, 1981 & $2305-0840$ & $\begin{array}{l}\text { Light westerly wind; traffic volume } \\
\text { and ambient pollutants began } \\
\text { to increase at } 0530 \text {; missed } \\
\text { first hour of fog, sampled } \\
\text { until fog lifted. }\end{array}$ & $\begin{array}{l}\text { Previous night foggy, smoggy } \\
\text { during day, } \mathrm{NO}_{x} \text { alert called } \\
\left(\mathrm{NO}_{x}=0.8 \mathrm{ppm}\right)\end{array}$ \\
\hline Lennox & December 18, 1981 & $2315-0043$ & $\begin{array}{l}\text { Light westerly wind; sampled from } \\
\text { beginning of log; fog } \\
\text { persisted until morning. }\end{array}$ & $\begin{array}{l}\text { Previous night foggy; high } \mathrm{NO}_{x} \\
\text { levels during day. }\end{array}$ \\
\hline Pasadena & December 20, 1981 & $745-845$ & $\begin{array}{l}\text { Light northerly wind; } 10^{\circ} \mathrm{C} \text {; fog } \\
\text { began before } 0700 ; \text { sampled } \\
\text { until fog lifted }\end{array}$ & Previous day was fair. \\
\hline Oildale & January 14, 1982 & $0200-0750$ & $\begin{array}{l}\text { Light southerly wind; } 3^{\circ}-4^{\circ} \mathrm{C} \text {, thin } \\
\text { fog. }\end{array}$ & $\begin{array}{l}\text { Overcast all of preceding } \\
\text { day; dense log on previous } \\
\text { night. }\end{array}$ \\
\hline Pasadena & January 17,1982 & $2130-2200$ & $\begin{array}{l}\text { Sample collected as fog } \\
\text { dissipated. }\end{array}$ & $\begin{array}{l}\text { Smog and haze during the } \\
\text { afternoon. }\end{array}$ \\
\hline Upland & May 14,1982 & $0630-0910$ & $\begin{array}{l}\text { Light and variable wind, } \\
12^{\circ} \mathrm{C} \text {, thin fog. }\end{array}$ & $\begin{array}{l}\text { Low clouds and ground haze } \\
\text { throughout night. }\end{array}$ \\
\hline
\end{tabular}




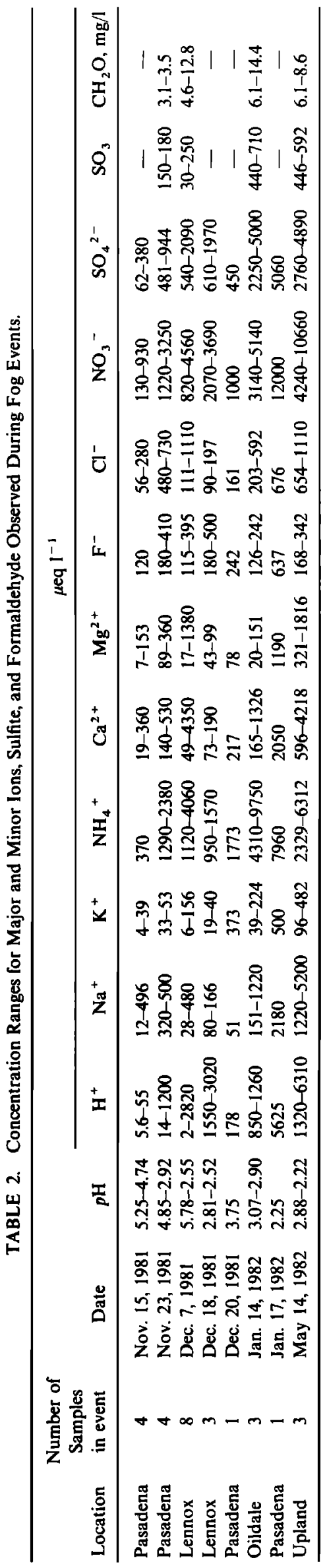

clean air days and smoggy days. The fogs in Lennox followed smoggy days. Oildale samples were collected during a period of extensive and persistent fog in the San Joaquin Valley. Samples at Upland were collected after dawn, when the haze that had been present during the night thickened enough to be collected.

The high and low concentrations of major ions, sulfite, and formaldehyde in fogwater during eight fog events are presented in Table 2. Concentrations of most ions in the second set of Pasadena samples, which followed a smoggy day, were higher than in the first Pasadena fog event. At Lennox the concentrations of major ions in fog were even higher than the Pasadena samples. Some of the fog samples from Lennox contained significant amounts of suspended solids. The greatest amount was in the final sample taken from the December 7 fog event during morning rush hour as the fog was dissipating.

The present sampling method does not differentiate between particles within droplets and particles greater than $8 \mu \mathrm{m}$ that are independent of water droplets. Because the minimum size for activating condensation nuclei in ambient fog is much smaller than the collector cutoff size, most particles collected in fog, with the exception of hydrophobic material, can be assumed to be associated with droplets.

A single fogwater sample collected in Pasadena on January 17 had exceptionally high concentrations. The sulfate and nitrate concentrations were the maximum values observed in any fog. Fogwater collected in Oildale also had very high nitrate and sulfate concentrations as well as the highest $\mathrm{NH}_{4}{ }^{+}, \mathrm{CH}_{2} \mathrm{O}$, and S(IV) concentrations. The Upland fog samples were also characterized by high levels of acidity and acidic anions.

Concentrations of trace metals in the fog samples were also elevated, as shown in Table 3. During some of the fog events, metal concentrations varied over an order of magnitude. The usual pattern was for high concentrations at the beginning and end of the event. Lead and iron concentrations exceeded $1.0 \mathrm{mg}$ $\mathrm{L}^{-1}(0.01 \mathrm{mM})$ on occasion.

The anion-to-cation ratios were close to unity for most of the samples, but there were discrepancies in some samples. In light of the large dilutions necessary to bring high concentrations down into suitable analytical ranges, the ion balances were reasonable. There were apparent excesses of cations in some of the samples that had large quantities of particles present. Calculation of the ion balance by using the concentrations of cations in filtered aliquots yielded better results. The aliquot for anions was routinely filtered prior to injection into the IC. This does not explain the apparent anion deficiency (or cation excess) in the fogwater samples collected from Oildale. The inclusion of $\mathrm{SO}_{3}{ }^{2-}$ in the anion sum does not completely make up the deficit either, however, sulfite in aliquots from these samples was not measured immediately. Even though preservation techniques were used, sulfite may be underestimated. Considering the high concentrations of aldehydes, it is probable that the corresponding carboxylic acids were present in the fogwater; this would account for some of the apparent anion deficiency. Other factors that may contribute to poor ionic balances are losses of ions to particle surfaces via sorption and formation of adducts and complexes of indeterminant charge.

\section{Discussion}

Figure 3 presents the ionic composition of individual fog samples as a function of time. Concentrations of all ions decrease sharply during the first few hours of the fogs in Lennox; however, the ionic proportions do not change appreciably. In most cases, concentrations in the fogwater rose as the fog 
TABLE 3. Ranges of Selected Trace-Metal Concentrations in Fog Samples

\begin{tabular}{|c|c|c|c|c|c|c|}
\hline \multirow[b]{2}{*}{ Site } & \multirow[b]{2}{*}{ Date } & \multicolumn{5}{|c|}{$\mu \mathrm{g} \mathrm{I}^{-1}$} \\
\hline & & $\mathrm{Fe}$ & $\mathbf{M n}$ & $\mathrm{Pb}$ & $\mathrm{Cu}$ & $\mathbf{N i}$ \\
\hline Pasadena & Nov. 15,1981 & $90-2,100$ & $18-160$ & $250-270$ & $1-15$ & $2-21$ \\
\hline Pasadena & Nov. 15,1981 & $920-1,770$ & $34-56$ & $1,310-2,540$ & $88-140$ & $8-14$ \\
\hline Lennox & Dec. 7,1981 & $356-23,700$ & $19-810$ & $820-2,400$ & $9-150$ & $2-52$ \\
\hline Lennox & Dec. 18,1981 & $1,020-2,080$ & $25-81$ & $1,700-2,350$ & $84-1,400$ & $32-54$ \\
\hline Pasadena & Dec. 20,1981 & 340 & 42 & 156 & - & - \\
\hline Oildale & Jan. 14,1982 & $240-6,400$ & $97-800$ & $241-366$ & $45-401$ & $124-586$ \\
\hline Upland & May 14,1982 & - & $430-570$ & $1,690-2,400$ & $156-185$ & $155-213$ \\
\hline
\end{tabular}

Number of samples per event is the same as for Table 2.

dissipated. The short duration fogs, which were usually very light fogs that resulted in low collection rates, also had high concentrations. Physical processes of droplet growth by accretion of water vapor, followed by evaporation, appear to account for this pattern.

Dilution by droplet growth could take place without any appreciable change in liquid water content (LWC) if the sedimentation rate was high enough to balance the condensation rate. Work by Roach et al. [1976] suggests that a significant portion of the liquid water formed during a fog event is lost, presumably to ground surfaces. During the periods over which concentrations were decreasing, collection rates, which are a function of LWC, remained constant. Advection of more dilute fog could account for this as well.

In Figures 4 and 5 the concentration of selected ions, normalized to their initial concentration, are depicted. If physical factors are responsible, the patterns will be nearly identical for ions that are controlled by the same factors or have common sources. The nearly hundredfold increase in $\mathrm{Ca}^{2+}$ and $\mathrm{Mg}^{2+}$, and the concomitant drop in $\mathrm{H}^{+}$concentration in the final two samples collected in the December 7 fog at Lennox, coincided with morning rush hour traffic, which would generate a large amount of road dust. Concentrations of other ions were increased during that period, as a result of evaporation, but not to the extent that $\mathrm{Ca}^{2+}$ and $\mathrm{Mg}^{2+}$ increases $(25$ times their initial concentrations); $\left[\mathrm{Na}^{+}\right]$and $\left[\mathrm{Cl}^{-}\right]$increased by a factor of 5 , and $\left[\mathrm{SO}_{4}{ }^{2-}\right],\left[\mathrm{NO}_{3}{ }^{-}\right]$, and $\left[\mathrm{NH}_{4}{ }^{+}\right]$returned to their initial concentrations. Acidity was nearly neutralized at the end of this log event. In association with the increased $\left[\mathrm{Ca}^{2+}\right]$ and $\left[\mathrm{Mg}^{2+}\right]$, an increase in suspended particles, $[\mathrm{Pb}]$ and $[\mathrm{Fe}]$, was observed at the same time as a rise in CO levels at Lennox, coinciding with the morning traffic. Transfer of gaseous $\mathrm{NH}_{3}$ into the droplets could account for the increase in $\left[\mathrm{NH}_{4}{ }^{+}\right]$and simultaneous drop in $\left[\mathrm{H}^{+}\right]$during the December 7 Lennox fog event, while the other ions were maintained at constant concentrations. However, if the $\mathrm{NH}_{3}$ had been present when the fog formed, it would have been immediately scavenged because of its high solubility at low $p \mathrm{H}$. Unless there was a local source for $\mathrm{NH}_{3}$, advective transport must be invoked to account for the apparent increase in $\left[\mathrm{NH}_{4}{ }^{+}\right]$.

In Pasadena, $\left[\mathrm{H}^{+}\right]$and $\left[\mathrm{NO}_{3}{ }^{-}\right]$simultaneously increased while the other ions were decreasing. This may be evidence for the nocturnal formation of $\mathrm{HNO}_{3}$ via the following reactions [Graham and Johnston, 1978]:

$$
\begin{gathered}
\mathrm{NO}+\mathrm{O}_{3} \longrightarrow \mathrm{NO}_{2}+\mathrm{O}_{2} \\
\mathrm{NO}_{2}+\mathrm{O}_{3} \longrightarrow \mathrm{NO}_{3}+\mathrm{O}_{2} \\
\mathrm{NO}_{2}+\mathrm{NO}_{3} \longrightarrow \mathrm{N}_{2} \mathrm{O}_{5} \\
\mathrm{~N}_{2} \mathrm{O}_{5}+\mathrm{H}_{2} \mathrm{O} \longrightarrow 2 \mathrm{HNO}_{3}
\end{gathered}
$$

Alternatively, the increase in $\mathrm{HNO}_{3}$ could result from scavenging or diffusion of fine aerosol to the droplets or by advection of fog with higher $\mathrm{NO}_{3}{ }^{-}$concentrations.

In nearly all the cases the dominant ions in the fog samples were $\mathrm{NO}_{3}{ }^{-}, \mathrm{SO}_{4}{ }^{2-}, \mathrm{H}^{+}$, and $\mathrm{NH}_{4}{ }^{+}$, which are the major components of secondary aerosol in Los Angeles [Cass, 1979]. These ions account for over $90 \%$ of the solutes in the initial stages of the Lennox samples. The highest concentrations were observed when the fog was preceded by smoggy days. Because secondary aerosols are effective condensation nuclei [Barrett et al., 1979], they will exert a considerable influence on the composition and concentration in logwater. When the concentration of secondary aerosol is high, the subsequent fogwater will also have high concentrations. The fraction of $\mathrm{NO}_{3}{ }^{-}$ and $\mathrm{SO}_{4}{ }^{2-}$ neutralized by $\mathrm{NH}_{3}$ (measured in terms of $\mathrm{NH}_{4}{ }^{+}$) will largely determine the free acidity of the fog that first deliquesces. In this connection it is noteworthy that the initial fogwater samples collected at Lennox are the most acidic, and subsequent samples during the event are progressively more neutral, while at Pasadena and Upland the converse is true.

If $\mathrm{HNO}_{3}$ and $\mathrm{NH}_{3}$ were present when the fog initially formed, they would be scavenged rapidly as well and influence the fogwater composition [Jacob and Hoffmann, 1983]. However, the combination of cooler temperatures and higher humidity before the onset of fog will probably force $\mathrm{NH}_{3}$ and $\mathrm{HNO}_{3}$ to condense into the particulate phase [Stelson and Seinfeld, 1982; Stelson, 1982], which can be scavenged via nucleation or diffusion as the fog forms.

Figure 6 is a conceptualization of the condensation/ evaporation cycle for fog droplets and illustrates the link between fogwater chemistry and the chemistry of smog and haze aerosol. High atmospheric concentrations of aerosol precursors appear to result in highly concentrated logwater. Likewise, dissipation of highly concentrated fog results in very concentrated and reactive aerosol. The high trace-metal content in fogs would catalyze $\mathrm{SO}_{2}$ oxidation. This link between fog and the subsequent aerosol can be seen in the correlation reported by Cass [1975] between morning fog and high humidity and high aerosol sulfate concentrations in the afternoon.

\section{The Role of Aldehydes in Fog Droplets}

Aldehydes are released as primary emissions from combustion sources and are generated photochemically from hydrocarbons [National Research Council, 1981]. The peroxide radical is an important byproduct of these reactions. Aldehydes are photochemically destroyed, with $\mathrm{OH} \cdot$ and $\mathrm{HO}_{2} \cdot$ as byproducts. Intermediates in aldehyde reaction pathways also play a role in the gas-phase reaction networks of $\mathrm{SO}_{2}$ and $\mathrm{NO}_{x}$.

Concentrations of formaldehyde as high as $0.5 \mathrm{mM}$ were present in the Los Angeles fogwater samples. Other aldehydes, 

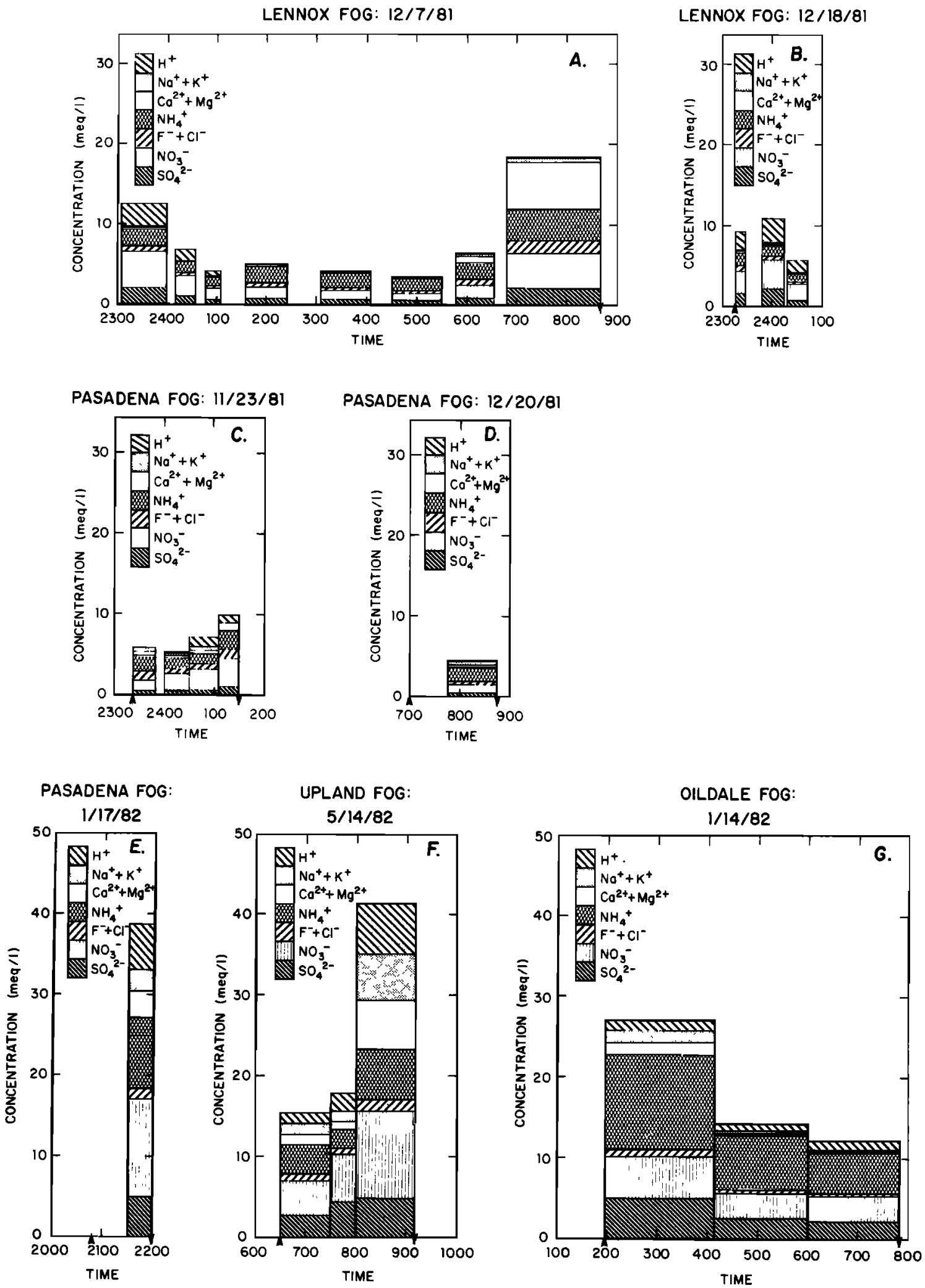

Fig. 3. Ionic composition as a function of time in sequential fog samples. Sampling interval is indicated by the width of each bar. The times of fog formation and dissipation are indicated by arrows.

such as acetaldehyde and benzaldehyde, are present in the Los Angeles atmosphere [National Research Council, 1981; Grosjean, 1982], and their presence in fogwater samples at comparable concentrations has been confirmed by the hydrazone derivative method [Fung and Grosjean, 1981]. Aldehydes react with $\mathrm{HSO}_{3}{ }^{-}$according to the following general stoichiometry:

$$
\mathrm{HSO}_{3}{ }^{-}+\mathrm{RCHO} \rightleftharpoons \mathrm{RHOCHSO}_{3}{ }^{-}
$$

The formation constant for the formaldehyde-bisulfite addition complex, HMSA, has a maximum of about $10^{5}$ between 
LENNOX FOG $12 / 07 / 81$
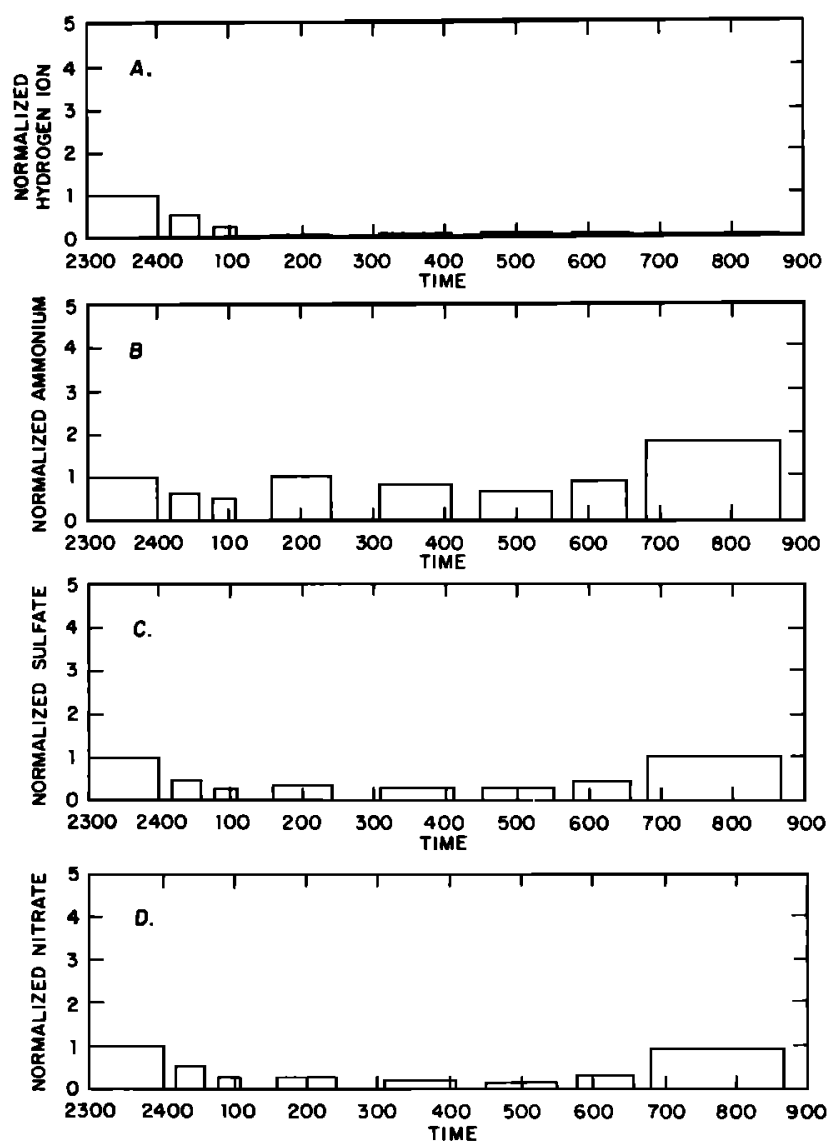

LENNOX FOG $12 / 07 / 81$
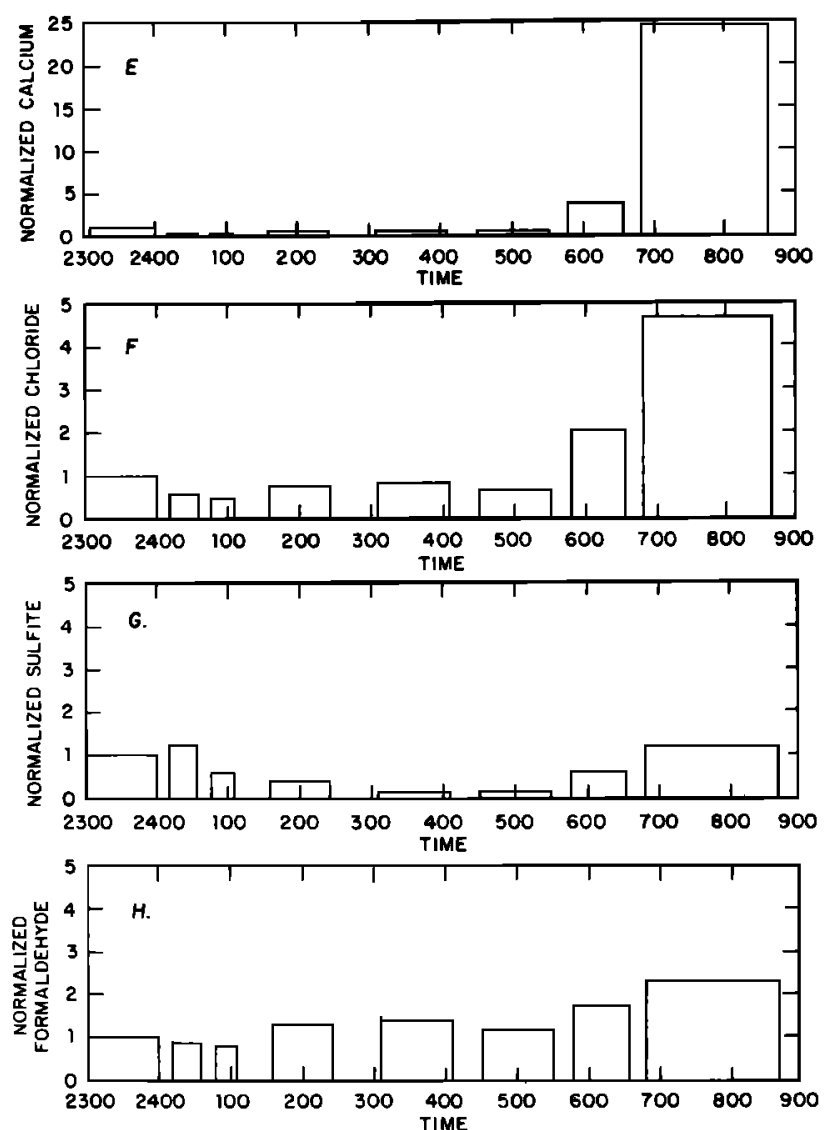

Fig. 4. $(a-h)$ Nondimensional concentrations of individual ions in fog collected on December 7-8, 1981, at the Lennox sampling site. Concentrations are normalized for each component with respect to the concentrations in the initial sample (1.e., $\hat{C}_{1}=C_{i} / C_{t, 0}$ ). Note the differences in scale. Sampling interval indicated by the width of each bar. NA indicates that a sample was not analyzed. Magnesium and sodium, which are not shown, were nearly identical to $\mathrm{Ca}^{2+}$ and $\mathrm{Cl}^{-}$, respectively.

pH 4 and 6 and drops to $10^{3}$ at pH 9 [Dasgupta et al., 1980]. Stewart and Donnally [1932] observed a similar pattern for the formation of the benzaldehyde-S(IV) adduct. They also observed an interaction between temperature and $p$ H. Ât low $p \mathrm{H}$ the temperature dependence of the equilibrium was stronger than at high $p \mathrm{H}$. Low temperature increased the stability of the complex. The molar ratio of formaldehyde to S(IV) in the fog samples ranged from 0.9 to 17 . Using Dasgupta's constants, the free $\mathrm{S}(\mathrm{IV})$ concentration in the fog ranges from $5 \%$ to $60 \%$ of the total. The equilibrium partial pressures of $\mathrm{SO}_{2}$ and $\mathrm{CH}_{2} \mathrm{O}$, required to achieve the $\mathrm{S}(\mathrm{IV})$ and $\mathrm{CH}_{2} \mathrm{O}$ values measured in the fogwater, were calculated from the following mass balance relationships:

$$
\begin{array}{r}
{[\mathrm{S}(\mathrm{IV})]=\left[\mathrm{SO}_{2}(\mathrm{aq})\right]+\left[\mathrm{HSO}_{3}{ }^{-}\right]+\left[\mathrm{SO}_{3}{ }^{2-}\right]} \\
+\sum_{i=1}^{n}\left[R_{i} \mathrm{CHOHSO}_{3}{ }^{-}\right]+\sum_{j=1}^{m}\left[M_{j} \mathrm{SO}_{3}\right] \\
{\left[R_{i} \mathrm{CHO}\right]_{\mathrm{T}}=\left[R_{1} \mathrm{CHO}\right]+\left[R_{i} \mathrm{CHOHSO}_{3}{ }^{-}\right]}
\end{array}
$$

where $R_{i}$ CHO represents aldehydes forming sulfonic acid adducts, and $M_{j}$ represents first-row transition metals forming stoichiometric sulfite complexes, Using the appropriate conditional equilibrium expressions for the concentration of the sulfonic acid adducts of $\mathrm{CH}_{2} \mathrm{O}, \mathrm{CH}_{3} \mathrm{CHO}, \mathrm{C}_{7} \mathrm{H}_{6} \mathrm{O}$, and the sulfitoiron(III) complex, and ignoring other $\mathrm{S}(\mathrm{IV})$ adducts and complexes because of their low potential concentrations, gives

$$
\begin{array}{r}
{[\mathrm{S}(\mathrm{IV})]=K_{\mathrm{H}} P_{\mathrm{SO}_{2}}\left(1+\frac{K_{a 1}}{\left[\mathrm{H}^{+}\right]}+\frac{K_{a 1} K_{a 2}}{\left[\mathrm{H}^{+}\right]^{2}}+\frac{K_{a 1} K_{a 2} \beta}{\left[\mathrm{H}^{+}\right]^{2}} \mathrm{Fe}(\mathrm{III})\right]} \\
\left.\quad+\sum_{i=1}^{n} \frac{K_{a 1}}{\left[\mathrm{H}^{+}\right]}\left[R_{i} \mathrm{CHO}\right] K_{A i}\right) \\
{\left[R_{1} \mathrm{CHO}\right]_{\mathrm{T}}=K_{H}{ }^{\prime} P_{R_{1} \mathrm{CHO}}\left(1+\frac{K_{a 1} K_{\mathrm{H}} P_{\mathrm{SO}_{2}}}{\left[\mathrm{H}^{+}\right]} K_{A i}\right)} \\
{[\mathrm{Fe}(\mathrm{III})]_{\mathrm{T}}=[\mathrm{Fe}(\mathrm{III})]+\left[\mathrm{Fe}(\mathrm{III}) \mathrm{SO}_{3}{ }^{-}\right]}
\end{array}
$$

where $\beta$ is the formation constant for an Fe(III) - S(IV) complex; $K_{H}{ }^{i}$ is Henry's Law constant for $R_{i}$ CHO; $K_{H}$ is Henry's Law constant for $\mathrm{SO}_{2} ; K_{a 1}$ and $K_{a 2}$ are acid dissociation constants; $K_{A i}$ is the bisulfite adduct formation constant, $\boldsymbol{P}_{\boldsymbol{R}_{\mathrm{CHO}} \mathrm{CHO}}$ and $\boldsymbol{P}_{\mathrm{SO}_{2}}$ are partial pressures.

Substitution of the aldehyde and metal mass balances into (12) gives

$$
\begin{aligned}
{[\mathrm{S}(\mathrm{IV})]=} & \frac{K_{H} P_{\mathrm{SO}_{2}}}{\left[\mathrm{H}^{+}\right]^{2}} \\
& {\left[\left[\mathrm{H}^{+}\right]^{2}+K_{a 1}\left[\mathrm{H}^{+}\right]+\frac{K_{a 1} K_{a 2} \beta[\mathrm{Fe}(\mathrm{III})]_{\mathrm{T}}\left[\mathrm{H}^{+}\right]^{2}}{\left(\left[\mathrm{H}^{+}\right]^{2}+\beta K_{a 1} K_{a 2} K_{H} P_{\mathrm{SO}_{2}}\right)}\right.} \\
& \left.+\sum_{i=1}^{n} \frac{K_{a 1} K_{A i}\left[\mathrm{H}^{+}\right]^{2}\left[R_{i} \mathrm{CHO}\right]_{\mathrm{T}}}{\left(\mathrm{H}^{+}+K_{a 1} K_{A i} K_{H} P_{\mathrm{SO}_{2}}\right)}\right]
\end{aligned}
$$

The appropriate equilibrium constants are given in Table 4. 
In the absence of adduct formation the equilibrium partial pressures of $\mathrm{CH}_{2} \mathrm{O}$ calculated from fogwater data range from $16 \mathrm{ppb}$ to $76 \mathrm{ppb}$, which are reasonable values for the Los Angeles atmosphere [Grosjean, 1982]. Adduct formation would lower the equilibrium partial pressure. The highest values of S(IV) found in some fog samples cannot be completely accounted for by aldehyde and iron-complex equilibria alone. Measured sulfite is $4-5$ times higher than the predicted equilibrium value, even with $P_{\mathrm{SO}_{2}}$ as high as $30 \mathrm{ppb}$ at the Los Angeles sites or $50 \mathrm{ppb}$ at Oildale, which are the highest values for those sites. The lower concentrations of S(IV), however, are comparable to the values predicted from equilibrium considerations. Stable organic and inorganic sulfite species in ambient aerosols have been demonstrated to exist [Izatt et al., 1978; Eatough et al., 1978]. Aldehydes may play an important role in the atmospheric chemistry of S(IV) as stabilizers that retard oxidation of S(IV), and possibly as sources of peroxides and free radicals through their photochemistry. More data on the aldehyde content of the atmosphere are necessary to ascertain their role in the heterogeneous chemistry of $\mathrm{SO}_{2}$.

\section{Nitrate to Sulfate Equivalent Ratios}

As is indicated in Figure $7,\left[\mathrm{NO}_{3}{ }^{-}\right]$in Pasadena and Lennox was about 2.5 times $\left[\mathrm{SO}_{4}{ }^{2-}\right]$; at Oildale and Upland the ratio

PASADENA FOG: $11 / 23 / 81$
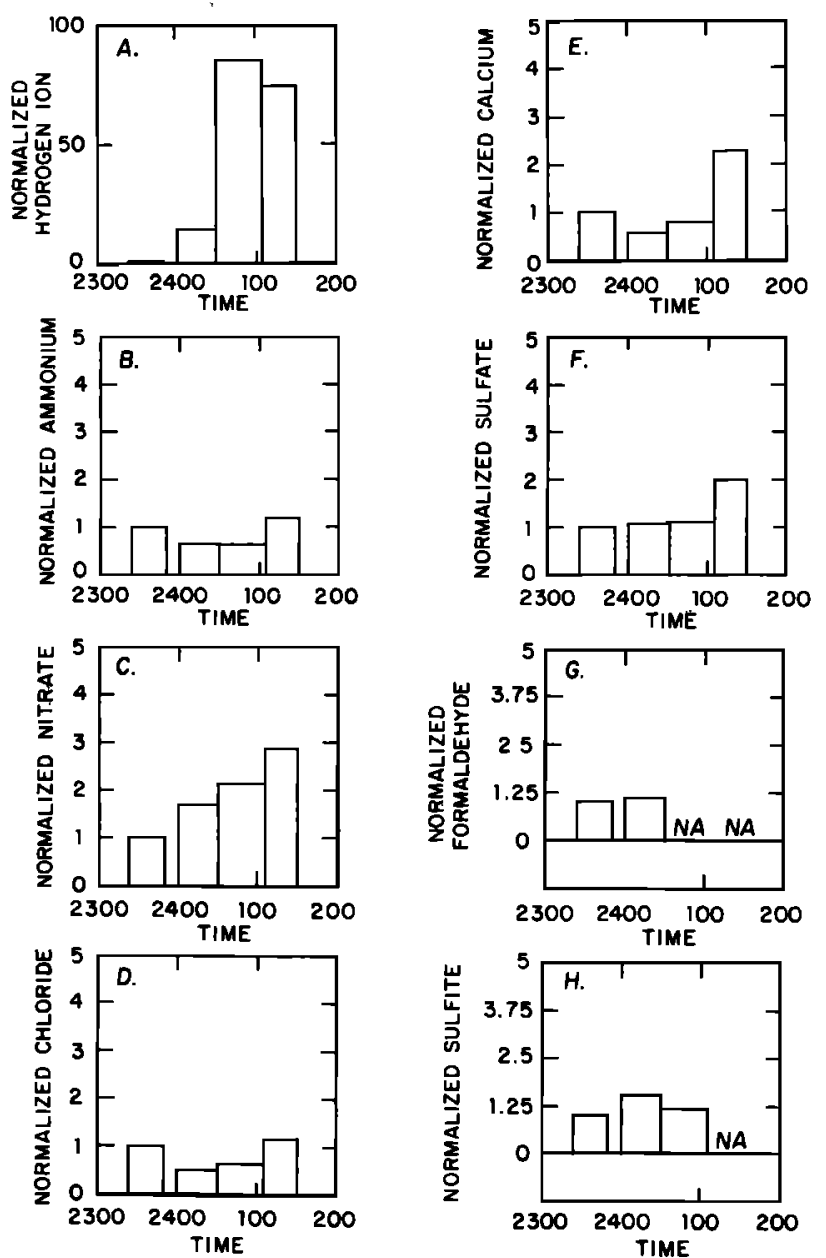

Fig. 5. $(a-h)$ Nondimensional concentrations of individual ions in fog collected on November 23-24, 1981, at the Pasadena sampling site. The normalization procedure and scales are described in Figure 4. was closer to $1: 1$. The nitrate to sulfate ratios in fogwater differ markedly from that observed in Los Angeles area rainwater [Liljestrand and Morgan, 1981]. In rainwater the equivalent ratio was less than 1 for coastal and central Los Angeles sites and increased to unity at Riverside at the eastern edge of the basin. Fogwater exhibited the opposite trend: $\left[\mathrm{NO}_{3}{ }^{-}\right]$exceeded $\left[\mathrm{SO}_{4}{ }^{2-}\right]$ at the coastal and central Los Angeles sites and decreased to near one at the most inland site (Upland). Beside the differences in their source strengths $\left(\mathrm{NO}_{x}\right.$ emissions exceed $\mathrm{SO}_{2}$ emissions by a factor of 2.5 in Los Angeles), there are important differences in the kinetics of their respective oxidations and scavenging processes, as is discussed by Jacob and Hoffmann [1983].

\section{Sodium ChloRide Ratios}

As Figure 8 illustrates, most of the fogwater samples had $\mathrm{Na}: \mathrm{Cl}$ ratios near that of seawater. There were a few samples with excess $\mathrm{Cl}^{-}$, which may be due to local sources. The highest excess of $\mathrm{Cl}^{-}$was found in Lennox fog during morning rush hour, which suggests lead bromochloride salts from automobile emissions as a possible $\mathrm{Cl}^{-}$source. Those samples also had high $[\mathrm{Pb}]$. Two of the samples with excess $\mathrm{Na}^{+}$were collected at the beginning of log events and may be affected by soil and dust. However, the other samples with excess $\mathrm{Na}^{+}$were extremely acidic. Reaction between marine aerosol and acidic gases or aerosol may be volatilizing $\mathrm{HCl}$ in the fog or the preceding aerosol as suggested by Eriksson [1960] and Hitchcock [1980]. The resulting fog would be deficient in $\mathrm{Cl}^{-}$.

\section{Comparison to Other Data}

Fog and cloudwater ionic concentrations as high as in some of these samples have been observed previously (see Table 5). At many of the sites, $p \mathrm{H}$ values were in the range 3 to 4 , but none were as low as the most extreme values for the Los Angeles area fogs. The concentration ranges for the cations $\mathrm{Na}^{+}, \mathrm{K}^{+}, \mathrm{Ca}^{2+}$, and $\mathrm{Mg}^{2+}$ in other regions overlap with the concentration ranges observed in Southern California. The extreme values reported here, which were found in light fogs and in the Lennox sample that was laden with particles, are somewhat higher. Ammonium concentrations are comparable, but the extreme values observed in this study are about 10 times the maxima for previously reported data. Sulfate concentrations are comparable to other reported values, while nitrate concentrations are considerably higher in the California fogs, which is to be expected because of the dominance of $\mathrm{NO}_{x}$ emissions. Furthermore, high concentrations of $\mathrm{HNO}_{3}$, which can be easily scavenged by fogwater, have been measured in the Los Angeles atmosphere [Appel, 1981].

Dense smog as a precursor gave rise to the most highly concentrated fogwater in Los Angeles. Other areas of the world subject to intense air pollution may also prove to have highly concentrated fogwater. Although ionic composition in the 1952 London fog was not measured, approximate calculations based on $\mathrm{SO}_{2}$ emission rates, measured $\mathrm{SO}_{2}$ concentrations, droplet residence time, and liquid water content [Wilkins, 1954a, b] gives $\mathrm{SO}_{4}{ }^{2-}$ concentrations of 11 to $46 \mathrm{meq}^{-1}$. For comparison, the extreme value measured during the winter of 19811982 in Southern California was $5 \mathrm{meq}^{-1}$.

\section{IMPLICATIONS}

Highly concentrated fogwater can have several important environmental effects. Sedimentation and impaction rates of 


\section{FOG: LINK BETWEEN ATMOSPHERIC AND WATER CHEMISTRY}

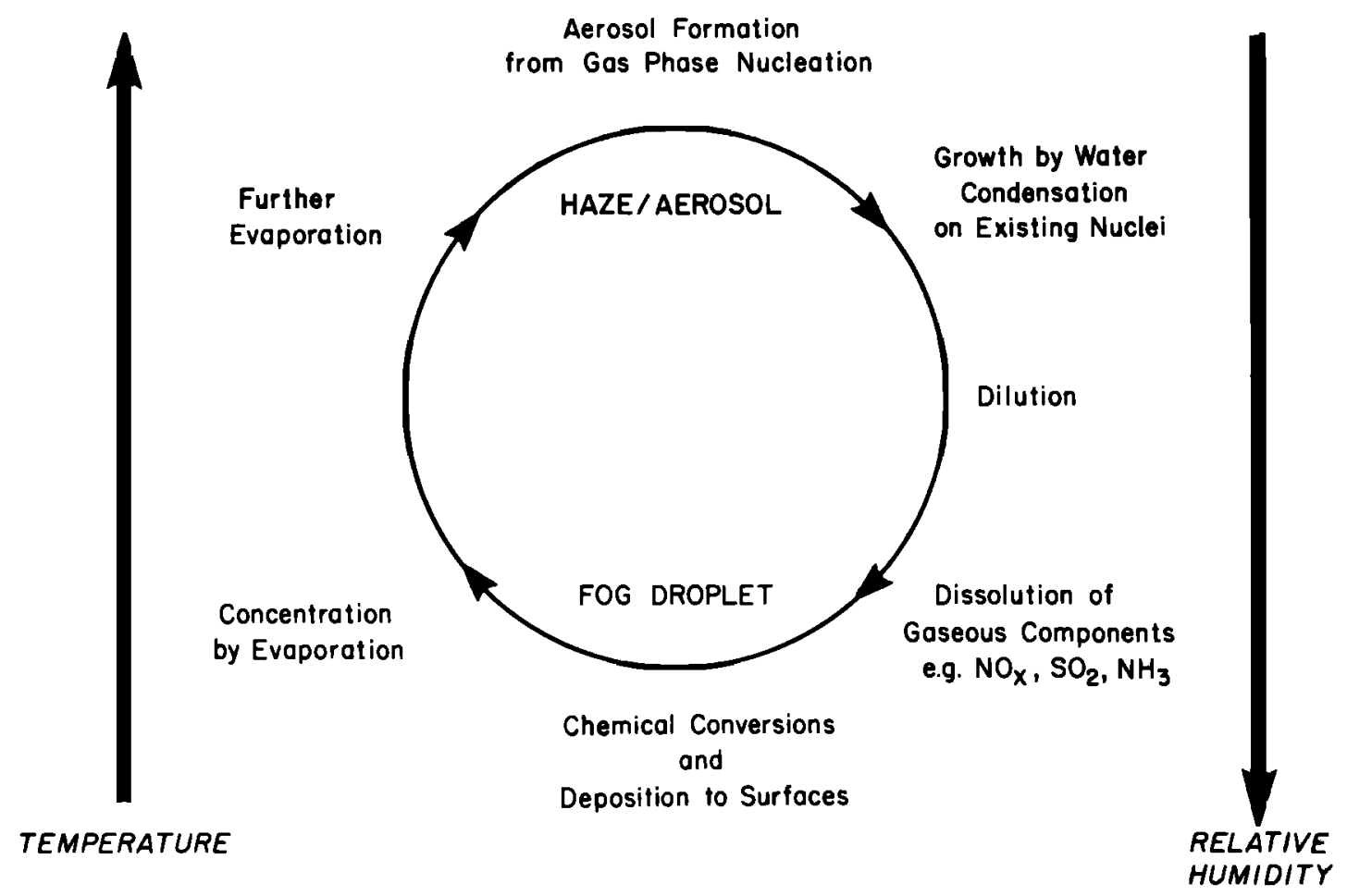

Fig. 6. A schematic diagram depicting the temperature and humidity dependence for fog formation and the apparent link between atmospheric gas phase and water phase chemistry.

TABLE 4. Equilibrium Constants Applicable to S(IV) and Aldehyde Chemistry

\begin{tabular}{|c|c|c|c|}
\hline & $\begin{array}{c}\mathrm{K} \\
M \text { or } M \text { atm }^{-1}\end{array}$ & $\begin{array}{l}\Delta \mathbf{H}^{\circ} 298 \\
\text { kcal mol }\end{array}$ & Reference \\
\hline $\mathrm{SO}_{2(\mathrm{~g})} \stackrel{\mathrm{K}_{\mathrm{H}}}{\rightleftharpoons} \mathrm{SO}_{2(\mathrm{aq})}$ & 1.245 & -6.247 & Sillén and Martell [1971] \\
\hline $\mathrm{SO}_{2 \text { (aq) }} \stackrel{\mathrm{K}_{\text {al }}}{\rightleftharpoons} \mathrm{H}^{+}+\mathrm{HSO}_{3}^{-}$ & $1.290 \times 10^{-2}$ & -4.161 & Sillén and Martell [1971] \\
\hline $\mathrm{HSO}_{3} \stackrel{-\mathrm{K}_{22}}{\rightleftharpoons} \mathrm{H}^{+}+\mathrm{SO}_{3}^{2-}$ & $6.014 \times 10^{-8}$ & -2.23 & Sillén and Martell [1971] \\
\hline $\mathrm{CH}_{2} \mathrm{O}_{(\mathrm{g})} \stackrel{\mathrm{K}^{\prime} \mathrm{H}}{\rightleftharpoons} \mathrm{CH}_{2} \mathrm{O}_{(\mathrm{aq})}$ & $6.3 \times 10^{3}$ & - & Ledbury and Blair [1925] \\
\hline $\mathrm{CH}_{2} \mathrm{O}_{(\mathrm{aq})}+\mathrm{HSO}_{3}-\stackrel{\mathrm{K}_{\mathrm{A}, 1}}{\rightleftharpoons} \mathrm{CH}_{2} \mathrm{OHSO}_{3}-$ & $\simeq 10^{5}$ & - & Dasgupta et al. $[1980]$ \\
\hline $\mathrm{Fe}^{3+}+\mathrm{SO}_{3}^{2-} \stackrel{\theta}{\rightleftharpoons} \mathrm{FeSO}_{3}^{+}$ & $\simeq 10^{10}-10^{18}$ & - & Carlyle [1971]; Harsen et al. [1976] \\
\hline $\mathrm{C}_{7} \mathrm{H}_{6} \mathrm{O}+\mathrm{HSO}_{3} \stackrel{\stackrel{\mathrm{K}_{\mathrm{A}}}{\rightleftharpoons}}{\rightleftharpoons} \mathrm{C}_{7} \mathrm{H}_{6} \mathrm{OHSO}_{3}-$ & $\simeq 10^{5}$ & - & Stewart and Donnally [1932] \\
\hline $\mathrm{C}_{2} \mathrm{H}_{4} \mathrm{O}+\mathrm{HSO}_{3}-\stackrel{\mathrm{K}_{\mathrm{A}}}{\rightleftharpoons} \mathrm{C}_{2} \mathrm{H}_{4} \mathrm{OHSO}_{3}-$ & $\simeq 10^{5}$ & - & by extrapolation \\
\hline
\end{tabular}




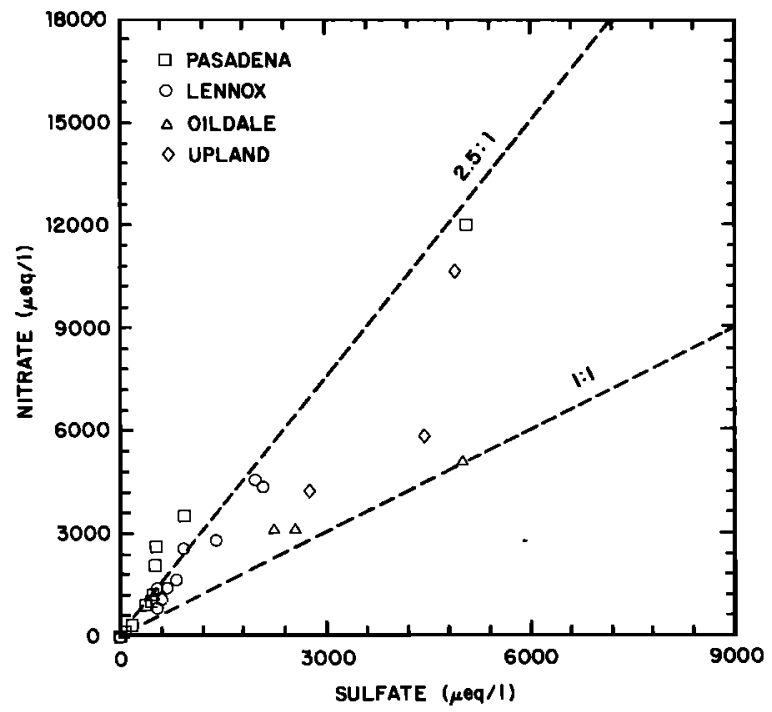

Fig. 7. Plot of nitrate and sulfate equivalent concentrations in fogwater. Dashed lines indicate 2.5:1 and 1:1 ratios.

fog droplets will be greater than for dry gas and aerosol. Roach et al. [1976] have calculated that up to $90 \%$ of the liquid water condensed during a fog event may sediment out on the ground. When winds accompany fog, interception of droplets by vegetation is also a major depositional pathway [Schlesinger and Reiners, 1974; Lovett and Reiners, 1982]. Measurement of rain and dry deposition fluxes alone may not adequately account for atmospheric loadings in regions where fog is frequent. Surface wetness from fog deposition may enhance deposition of $\mathrm{SO}_{2}$

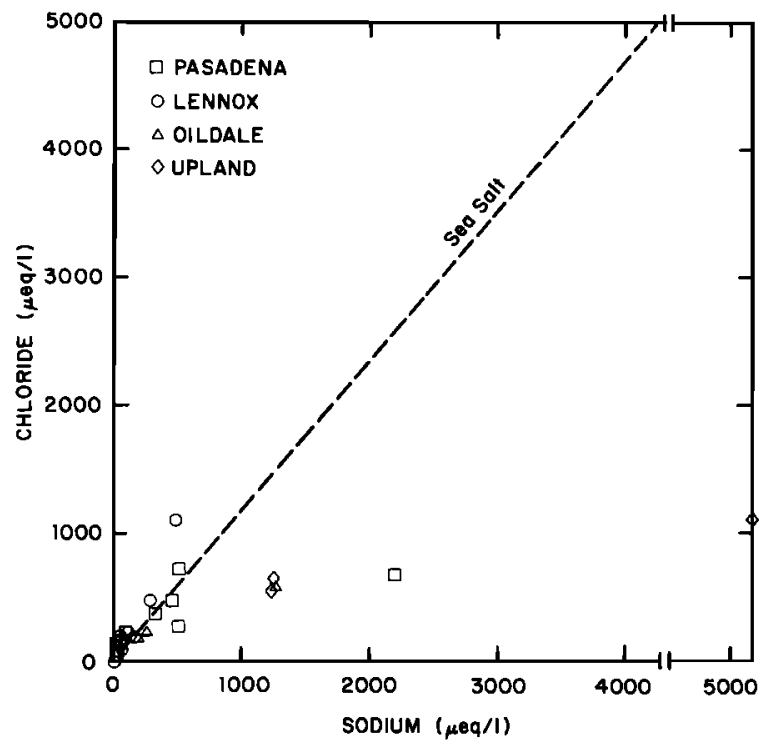

Fig. 8. Plot of sodium and chloride concentrations. Dashed line indicates the $\mathrm{NaCl}$ ratio in seawater. and subsequent oxidation to $\mathrm{SO}_{4}{ }^{2-}$ (with a possible involvement of trace metals) [Lindberg et al., 1979].

Fogwater deposited on leaf surfaces is highly efficient in leaching ions from the leaves [Tukey, 1979] and may result in some plant injury. Experiments with acid mists show plant injury occurring at $p \mathrm{H}$ levels around 3 [Jacobson, 1980], which is typical of fogwater in parts of Southern California. Damage to building materials and metal surfaces is also possible from deposition of acidic fog. Corrosion of statuary and building materials has been observed in several locations throughout the world. The role of fog in this damage is not known, although research [Metropolitan Museum of Art, 1979] on the Horses of San Marco (ca. 100 B.C.) in Venice, Italy, indicates that fog and high $\mathrm{SO}_{2}$ concentrations have resulted in significant damage during the last 50 years.

Historically, fogs have been implicated in a number of severe pollution episodes that caused increased human mortality [Environmental Protection Agency, 1971]. The most notable of these is the infamous London Fog of 1952 [Wilkins, 1954a, b], which caused 4000 excess deaths during the 5-day episode and 12,000 deaths over 4 months. Further research is needed to ascertain whether the fog caused mortality or was merely a consequence of the severe inversion conditions that caused a build up of toxic air pollutants, which were the true agents of mortality. Previous analysis [Larsen, 1970] suggested that these deaths correlated well with the product of gas-phase $\mathrm{SO}_{2}$ and particle concentrations; however, sulfuric acid mists have been implicated [Wilkins, 1954a,b].

\section{Conclusion}

Fogwater in Southern California provides a propitious environment for the scavenging of particulate and gaseous forms of $\mathrm{S}(\mathrm{IV}), \mathrm{S}(\mathrm{VI}), \mathrm{N}(\mathrm{V})$, and $\mathrm{N}(-\mathrm{III})$; for the subsequent conversion of S(IV) to S(VI); and for the concomitant production of acidity. Unusually high concentrations of $\mathrm{SO}_{4}{ }^{2-}, \mathrm{NO}_{3}{ }^{-}, \mathrm{NH}_{4}{ }^{+}$, and $\mathrm{H}^{+}$were observed. The highest concentrations were observed during fog events preceded by smoggy days. Acidity caused by $\mathrm{NO}_{3}{ }^{-}$and $\mathrm{SO}_{4}{ }^{2-}$ precursors was neutralized to some extent by scavenging of $\mathrm{NH}_{3}$ and calcareous dust.

The physical processes of condensation and evaporation, along with scavenging and subsequent chemical conversion of reactive gas-phase components, appear to mutually control the temporal trends in fogwater composition. The apparent cyclical relationship between the occurrence of smog and fog in the Los Angeles basin is a manilestation of this phenomenon. The late night and early morning fogs, which form more readily in a particle-laden atmosphere, appear to accelerate and enhance smog production, visibility reduction, and particulate sulfate levels during the subsequent day. This relationship can be dubbed the smog-fog-smog cycle.

Clearly, more research is needed to elucidate the mechanisms by which fog-processed aerosols become highly reactive sites for daytime photochemical transformations. The role of aldehydes and transition metals in the transport and transformation of S(IV) in atmospheric water droplets needs to be explored more intensively. Furthermore, given the millimolar concentrations of some of the metal ions in urban $\int 0 g$, the effect of metal ion catalysts on important chemical transformations (e.g., S(IV) to S(VI)) needs to be considered more carefully in the development of quantitative air quality models for urban airsheds. 


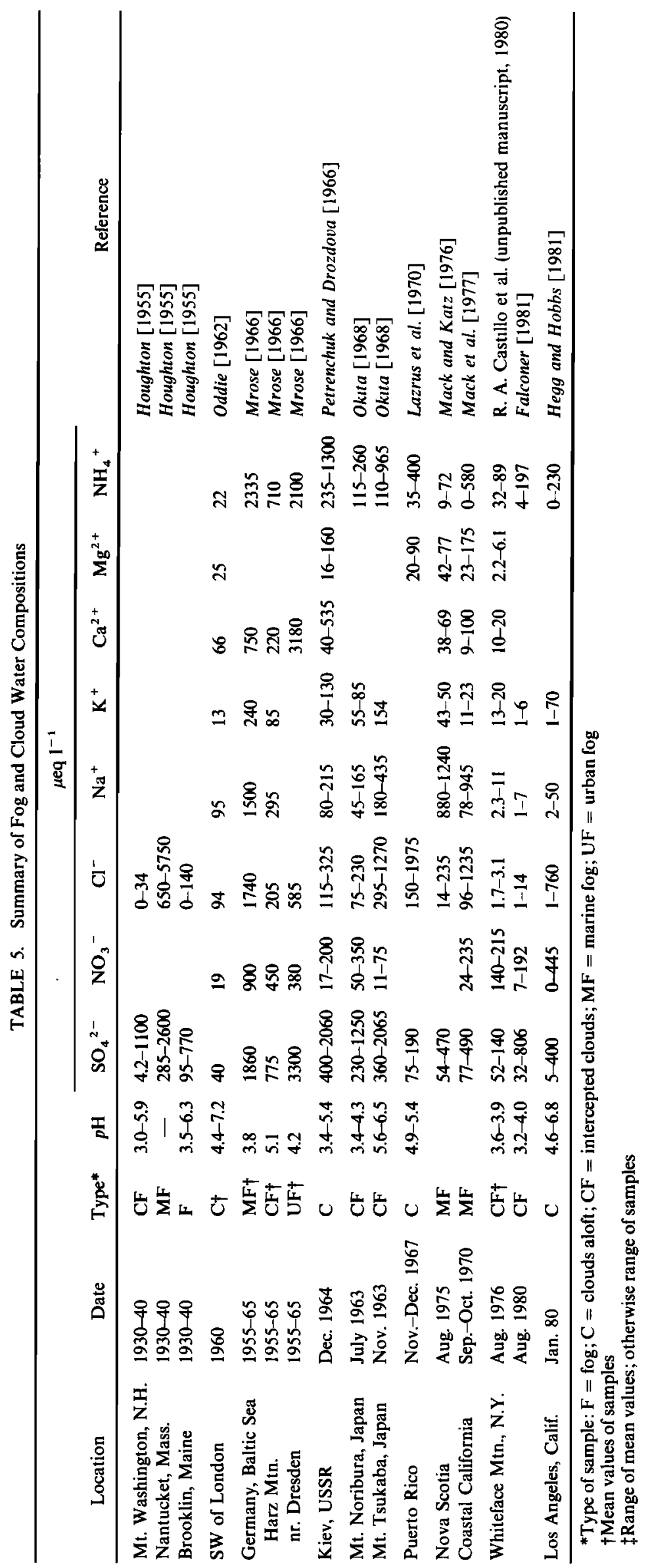


Acknowledgments. We gratefully acknowledge the financial support of the California Air Resources Board and the invaluable assistance provided by its professional staff. Additional logistical support was provided by the South Coast Air Quality Management District. Special thanks are extended to R. C. Flagan, J. J. Morgan, D. Lawson, and D. Grosjean for their contributions to the success of this research.

\section{REFERENCES}

Appel, B. R., Y. Tokiwa, and M. Haik, Sampling of nitrates in ambient air, Atmos. Environ., 15, 283-289, 1981.

Baboolal, B., H. R. Pruppacher, and J. H. Topalian, A sensitivity study of a theoretical model of $\mathrm{SO}_{2}$ scavenging by water drops in air, $J$. Atmos. Sci., 38, 856-870, 1981.

Barrett, E., F. P. Parungo, and R. F. Pueschel, Cloud modification by urban pollution: A physical demonstration, Meteorol. Res., 32, 136$149,1979$.

Carlyle, D. W., A kinetic study of the aquation of sulfitoiron(III) ion, Inorg. Chem., 10, 761-764, 1971.

Cass, G. R., Dimensions of the Los Angeles $\mathrm{SO}_{2} /$ sulfate problem, Memo. I5, Environ. Qual. Lab., Calif. Inst. Technol., Pasadena, California, 1975.

Cass, G. R., On the relationship between sulfate air quality and visibility with examples in Los Angeles, Atmos. Environ., 13, 1069-1084, 1979.

Cass, G. R., Sulfate air quality control strategy design, Atmos. Environ., $15,1227-1249,1981$.

Cass, G. R., and F. H. Shair, Transport of sulfur oxides within the Los Angeles sea breeze/land breeze circulation system, paper presented at Joint Conference on Application of Air Pollution Meteorology, Am. Meteorol. Soc., New Orleans, March 24-27, 1980.

Cox, R. A., Particle formation from homogeneous reactions of sulfur dioxide and nitrogen dioxide, Tellus, 26, 235-240, 1974.

Dasgupta, P. K., K. De Cesare, and J. C. Ullrey, Determination of atmospheric sulfur dioxide without tetrachloromercurate(II) and the mechanism of the Schiff reaction, Anal. Chem., 52, 1912-1922, 1980.

Eatough, D. J., T. Major, J. Ryder, M. Hill, N. F. Mangelson, N. L. Eatough, L. D. Hansen, R. G. Meisenheimer, and J. W. Fischer, The formation and stability of sulfite species in aerosols, Atmos. Environ., 12, 263-271, 1978.

Environmental Protection Agency, Guide for Air Pollution Avoidance, Appendix B, History of Episodes, Rep. PH-22-68-32, pp. 123-135, Washington, D.C., 1971.

Eriksson, E., The yearly circulation of chloride and sulfur in nature: Meteorological, geochemical, and pedological implications, Part 2. Tellus, 12, 63-109, 1960.

Falconer, P. D., Cloud Chemistry and Meteorological Research at Whiteface Mountain: Summer 1980, ASRC Publ. 806, Atmos. Sci. Res. Center, State Univ. New York, Albany, 1981

Fortune, C. R., and B. Dellinger, Stabilization and analysis of sulfur(IV) aerosols in environmental samples. Environ. Sci. Technol., 16, $62-66,1982$.

Fung, K., and D. Grosjean, Determination of nanogram amounts of carbonyls as 2,4-dinitrophenylhydrazones by high-performance liquid chromatography, Anal. Chem., 53, 168-181, 1981.

Galloway, J. N., G. E. Likens, W. C. Keene, and J. M. Miller, The composition of precipitation in remote areas of the world, J. Geophys. Res., 87, 8771-8786, 1982.

Graham, R. A., and H. S. Johnston, The photochemistry of $\mathrm{NO}_{3}$ and the kinetics of the $\mathrm{N}_{2} \mathrm{O}_{5}-\mathrm{O}_{3}$ system, J. Phys. Chem., 82, 254-268, 1978.

Grosjean, D., Formaldehyde and other carbonyls in Los Angeles ambient air, Environ. Sci. Technol., 16, 254-262, 1982.

Hansen, L. D., L. Whiting, D. J. Eatough, T. E. Jensen, and R. M. Izatt, Determination of sulfur(IV) and sulfate aerosols by thermometric methods, Anal. Chem., 48, 634-638, 1976.

Hitchcock, D. R., Sulfuric acid aerosols and $\mathrm{HCl}$ release in coastal atmospheres: Evidence of rapid formation of sulfuric acid particulates, Atmos. Environ., 14, 165-182, 1980.

Hegg, D. A., and P. V. Hobbs, Cloudwater chemistry and the production of sulfates in clouds, Atmos. Environ., 15, 1597-1604, 1981.

Hoffmann, M. R., and D. J. Jacob, Kinetics and mechanisms of the catalytic oxidation of dissolved sulfur dioxide in aqueous solution: An application to nighttime fog-water chemistry, in Acid Precipitation, vol. 6, edited by J. G. Calvert, Ann Arbor Science Publishers, Ann Arbor, Michigan, 1983.

Houghton, H. G., On the chemical composition of fog and cloud water, J. Meteorol., I2, 355-357, 1955.
Humphrey, R. E., M. H. Ward, and W. Hinze, Spectrophotometric determination of sulfite with 4,4-dithiopyridine and 5,5-dithiobis(2nitrobenzoic acid), Anal. Chem., 42, 698-702, 1970.

Izatt, R. M., D. J. Eatough, M. L. Lee, T. Major, B. E. Richter, L. D. Hansen, R. G. Meisenheimer, and J. W. Fischer, The formation of inorganic and organic S(IV) species in aerosols, in Proceedings of the 4th Joint Conference on Sensing Environmental Pollutants, pp. 821824, American Chemical Society, Washington, D.C., 1978.

Jacob, D. J., and M. R. Hoffmann, A dynamic model for the production of $\mathrm{H}^{+}, \mathrm{NO}_{3}{ }^{-}$, and $\mathrm{SO}_{4}{ }^{2-}$ in urban fog, submitted to J. Geophys. Res., 1982

Jacob, D. J., R. C. Flagan, J. M. Waldman and M. R. Hoffmann, Design and calibration of rotating-arm collectors for ambient fog sampling, paper presented at 4th International Conference on Precipitation Scavenging, Dry Deposition, and Resuspension, Nov. 29Dec. 3, Santa Monica, Calif., 1982.

Jacobson, J. S., Experimental studies on the phytotoxicity of acidic precipitation: The United States experience in Effects of Acid Precipitation on Terrestrial Ecosystems, edited by T. C. Hutchinson and M. Havas, pp. 151-160, Plenum, New York, 1980.

Larsen, R. I., Relating air pollutant effects to concentration and control, J. Air Pollut. Control Assoc., 20, 214-225, 1970.

Lazrus, A. L., H. W. Baynton, and J. P. Lodge, Trace constituents in oceanic cloud water and their origin, Tellus, 22, 106-113, 1970.

Ledbury, W., and E. W. Blair, The partial formaldehyde vapour pressure of aqueous solutions of formaldehyde, Part 2, J. Chem. Soc., $127,2832-2839,1925$.

Liljestrand, H. M., and J. J. Morgan, Spatial variations of acid precipitation in Southern California, Environ. Sci. Technol., 15, 333-338, 1981.

Lindberg. S. E., R. C. Harriss, R. R. Turner, D. S. Shriner, and D. D. Huff, Mechanism and rates of atmospheric deposition of selected trace element and sulfate to deciduous forest watershed, Rep. ORNL/TM-6674, Oak Ridge Nat. Lab., Oak Ridge, Tenn. 1979.

Lovett, G. M., and W. A. Reiners, Deposition of cloudwater and dissolved ions to subalpine forests of New England, paper presented at 4th International Conference on Precipitation Scavenging, Dry Deposition, and Resuspension, sponsor, Santa Monica, Calif,, Nov. 29-Dec. 3, 1982

Mack, E. J., and U. Katz, The Characteristics of Marine Fog Occurring off the Coast of Nova Scotia, Rep. CJ-5756-M-1, Calspan Corp. Buffalo, New York, 1976

Mack, E. J., U. Katz, C. W. Rogers, D. W. Gaucher, K. R. Piech, C. K. Akers, and R. J. Pilié, An Investigation of the Meteorology, Physics and Chemistry of Marine Boundary Layer Processes, Rep. CJ-6017$M-1$, Calspan Corp., Buffalo, New York, 1977.

Mack, E. J., and R. J. Pilie, Fog Water Collector, U.S. Patent 3889532 , 1975.

Martin, L. R., Kinetic studies of sulfite oxidation in aqueous solution, in Acid Precipitation: SO, NO, NO, Oxidation Mechanisms: Atmospheric Considerations, edited by J. G. Calvert, Ann Arbor Science Publishers, Ann Arbor, Mich., 1983.

McMurry, P. H., D. J. Rader, and J. L. Smith, Studies of aerosol formation in power plant plumes, 1, Parameterization of conversion rate for dry, moderately polluted ambient conditions, Atmos. Environ., 15, 2315-2329, 1981 .

Metropolitan Museum of Art, The Horses of San Marco, Venice, translated from Italian by J. and V. Wilton-Ely, New York, 1979.

Morgan, J. J., and H. J. Liljestrand, Measurement and interpretation of acid rainfall in the Los Angeles basin, Rep. $A C-2-80$, W. M. Keck Lab. Hydraul. Water Resour., Calif. Inst. Technol., Pasadena, California, 1980

Mrose, H., Measurement of $\mathrm{pH}$ and chemical analyses of rain-, snow-, and fog-water, Tellus, 18, 266-270, 1966.

Nash, T., The colorimetric estimation of formaldehyde by means of the Hantzsch reaction, Biochem. J., 55, 416-421, 1953.

National Research Council, Formaldehyde and Other Aldehydes, National Academy Press, Washington, D. C., 1981.

Oddie, B. C. V., The chemical composition of precipitation at cloud levels, Quart. J. R. Meteorol. Soc., 88, 535-538, 1962.

Okita, T., Concentrations of sulfate and other inorganic materials in fog and cloud water and in aerosol, J. Meteorol. Soc. Jpn., 46, $120-126,1968$.

Petrenchuk, O. P., and V. M. Drozdova, On the chemical composition of cloud water, Tellus, $18,280-286,1966$

Rietz, E. B., The stabilization of small concentrations of formaldehyde in aqueous solutions, Anal. Lett., 13, 1073-1084, 1980. 
Roach, W. T., R. Brown, S. J. Caughey, J. A. Garland, and C. J. Readiness, The physics of radiation fog, 1 , A field study, Quart. J. $R$. Meteorol. Soc., 10, 313-33, 1976.

Sander, S. P., and J. H. Seinfeld, Chemical kinetics of homogeneous oxidation of sulfur dioxide, Environ. Sci. Technol., 10, 1114-1123, 1976.

Schlesinger, W. H., and W. A. Reiners, Deposition of water and cations on artificial foliar collectors in fir Krummholz of New England mountains, Ecology, 55, 378-386, 1974.

Schwartz, S. E., Gas-aqueous reactions of sulfur and nitrogen oxides in liquid-water clouds, in Acid Precipitation: $\mathrm{SO}_{2}, \mathrm{NO}$, and $\mathrm{NO}_{2} \mathrm{Oxida}$ tion Mechanisms: Atmospheric Considerations, edited by J. G. Calvert, Ann Arbor Science Publishers, Ann Arbor, Mich., 1983.

Sillén. L. G., and A. E. Martell, Stability Constants of Metal-Ion Complexes, Suppl, I, 2nd ed., The Chemical Society, London, 1971.

Smith, F. B., and G. H. Jeffrey, Airborne transport of sulphur dioxide from the U.K., Atmos. Environ., 9, 643-659, 1975

Solórzano, L., Determination of ammonia in natural waters by the phenolhypochlorite method, Limnol. Oceanogr., 14, 799-801, 1967.

Stelson, A. W., Thermodynamics of aqueous atmospheric aerosols, Ph.D. thesis, 127 pp., Calif. Inst. Technol., Pasadena, California, 1982.

Stelson, A. W., and J. H. Seinfeld, Relative humidity and temperature dependence of the ammonium nitrate dissociation constant, Atmos. Environ., 16, 983-992, 1982.

Stewart, T. D., and L. H. Donnally, The aldehyde bisulfite compounds, 2 , The effect of varying hydrogen ion and of varyirig temperature upon the equilibrium between benzaldehyde and bisulfite ion, J. Am. Chem. Soc., 54, 3555-3558, 1932.

Tukey, H. B., Jr., The leaching of substances from plants, Ann. Rev. Plant Physiol., 71, 305-324, 1970.

Waldman, J. M., J. W. Munger, D. J. Jacob, R. C. Flagan, J. J. Morgan, and M. R. Hoffmann, Chemical composition of acid fog, Science, $218,677-680,1982$.

Wilkins, E. T., Air pollution and the London fog of December 1952, $J$. R. Sanit. Inst., 74, 1-21, 1954a.

Wilkins, E. T., Air pollution aspects of the London fog of December 1952, J. R. Meteorol. Soc., 80, 267-278, $1954 b$.

Wilson, J. C., and P. H. McMurry, Studies of aerosol formation in power plant plumes, 2 , Secondary aerosol formation in the Navajo generating station plume, Atmos. Environ., 15, 2329-2339, 1981.

(Received October 4, 1982;

revised February 4, 1983;

accepted February 17, 1983.) 